tomia, dysgeusia, fatigue, hair loss, pneumonia, herpes zoster, neutropenia and thrombocytopenia. Side effects were less frequent following 750 rad. No bacterial sepsis has occurred in either group. A sustained lymphopenia was seen in both groups $(p<0.01)$, with a significant reduction in Leu-2a $(p<0.01)$ and Leu-3a $(p<0.01)$ positive lympho cytes. The Leu-3a/Leu-2a ratio was reduced in 16 patients. Responses of peripheral blood mono nuclear cells to PHA were significantly reduced following 2000 rad $(p<0.01)$ and 750 rad' $(p<$ 0.05 ). There was no reduction in serum immunoglobulin or rheumatoid factor levels. Thus, similar clinical and immunological modification of intractable RA occurred following 750 rad and 2000 rad. Short term toxicity was less marked following 750 rad and septic sequelae did not occur in either group.

THERMOGRAPHY IS MORE SENSITIVE THAN SCINTIGRAPHY IN THE DIAGNOSIS OF ALGODYSTROPHY

R. J. Coughlan; A. J. Crisp, B. L. Hazleman, G. Parr, D. P. Page Thomas. Rheumatology Research Unit, Addenbrooke's Hospital, Cambridge, U.K.

Algodystrophy is characterised by pain, vasomotor instability, atrophy of soft tissues in a limb or part of a limb without serological evidence of inflammation. Trauma is a precipitating event in many but not all patients. The pathological mechanisms that lead to algodystrophy are unknown but are thought to be mediated by disturbance in autonomic function in the affected limb. The criteria used for the diagnosis of algodystrophy include the features already described as well as increased uptake of technetium on bone scanning. Osteoporosis is frequently present in severe cases but may not be present in milder forms of the syndrome. Abnormal uptake on bone scintigraphy is present in the majority of patients with algodystrophy. Thermography is a sensitive and simple method of detecting alterations in skin temperature and in this study was used to assess vasomotor abnormalities.

Twelve patients with clinically suspected algodystrophy on the basis of limb pain for over three months, bone tenderness and symptoms or signs of vasomotor disturbance in the absence of a mechanical or inflammatory lesion were enrolled in the study. Each was examined by X-ray, scintigraphy and thermography. Five patients had radiologically detectable osteoporosis, eight had abnormal bone scans and all twelve had thermographic abnormalities. The four patients with normal bone scans included two patients with bilateal disease and two with very mild asymmetry not considered pathological. These data would suggest that thermogfraphy is more sensitive than other investigations in the diagnosis of algodystrophy insofar as it can objectively demonstrate autonomic disturbance that possibly underlies this condition.

DETECTION AND PARTIAL CHARACTERIZATION OF HUMAN B-CELL COLONY STIMULATING ACTIVITY IN SYNOVIAL FLUIDS OF PATIENTS WITH RHEUMATOID ARTHRITIS

A. C. Fay*, A. Trudgett, J. D. McCrea, F. Kirk, J. M. Thompson, E. S. Mitchell, M! J. W. Boyd, S. D. Roberts and T. A. McNeill. Department of Microbiology and Immunology, The Queen's University of Belfast, Belfast; Departments of Rheumatology, Royal Victoria and Musgrave Park Hospitals, Belfast, and The Laboratories, Musgrave Park Hospital, Btlfast, U.K.

The joint fluids of thirty-seven patients with rheumatoid arthritis, eight patients with traumatic injuries to their joints, two patients with Reiter's syndrome and thifree patients with psoriatic arthritis were tested for the presence of B-cell colony stimulating activity (B-cell CSA). B-cell CSA was found in all of the joint fluids from the patients with traumatic injuries to their joints or in the joint fluids from the patients with Reiter's syndrome. A trace of B-cell CSA was found in the joint fluid of one of the three patients with psoriatic arthritis. There was a positive correlation $(r=0.796)$ between the amount of rheumatoid factor present in the joint fluids and the titre of B.cell CSA. This correlation was highly significant $(P<0.001)$. The B-cell CSA was localised to component (s) with molecular weight ranges 115-129 $\mathrm{Kd}$ and $64-72 \mathrm{Kd}$ and an isoelectric point of 6.8. Its activity was sensitive to reduction with 2-mercaptoethanol and to the oxidising action of potassium periodate.

\title{
CORRECTION
}

\section{PROCEEDINGS OF THE IRISH NEUROLOGICAL ASSOCIATION}

20th Annual Meeting in May, 1984.

Abstract of the paper on

\section{"SYMPTOMATIC SUBEPENDYMOMA OF THE FOURTH VENTRICLE : CASE REPORT"}

The editor regrets the omission of the main author T. P. G. Doorly from the text published in the June 1985 issue of the Journal. 